\title{
Multiwall Carbon Nanotube Coated with Conducting Polyaniline Nanocomposites for Quasi-Solid-State Dye-Sensitized Solar Cells
}

\author{
Mohammad Rezaul Karim, ${ }^{1}$ Ashraful Islam, ${ }^{2}$ M. D. Akhtaruzzaman, ${ }^{3}$ \\ Liyuan Han, ${ }^{2}$ and Abdurahman Al-Ahmari ${ }^{1,4}$ \\ ${ }^{1}$ Center of Excellence for Research in Engineering Materials (CEREM), College of Engineering, King Saud University, \\ Riyadh 11421, Saudi Arabia \\ ${ }^{2}$ Photovoltaic Materials Unit, National Institute for Materials Science, 1-2-1 Sengen, Tsukuba, Ibaraki 305-0047, Japan \\ ${ }^{3}$ Department of Chemistry, Faculty of Science, University of Malaya, 50603 Kuala Lumpur, Malaysia \\ ${ }^{4}$ Department of Industrial Engineering, College of Engineering, King Saud University, Riyadh 11421, Saudi Arabia
}

Correspondence should be addressed to Mohammad Rezaul Karim, mkarim@ksu.edu.sa

Received 30 June 2012; Accepted 25 September 2012

Academic Editor: Ahmed El-Shafei

Copyright (c) 2013 Mohammad Rezaul Karim et al. This is an open access article distributed under the Creative Commons Attribution License, which permits unrestricted use, distribution, and reproduction in any medium, provided the original work is properly cited.

\begin{abstract}
Multiwalled carbon nanotube (MWNT) coated with conducting polyaniline (PAni) nanocomposites has been enforced as for quasisolid-state electrolyte layer in the dye-sensitized solar cells (DSSCs), and the incorporation of MWNT-PAni nanoparticles on the cell performance has been examined. The MWNT-PAni nanoparticles exploited as the extended electron transfer materials, which can reduce charge diffusion length and serve simultaneously as catalyst for the electrochemical reduction of $\mathrm{I}_{3}{ }^{-}$. An ionic liquid of 1-methyl-3-propyl-imidazolium iodide (PMII) together with the hybrid MWNT-PAni nanocomposites was placed between the dye-sensitized porous $\mathrm{TiO}_{2}$ and the Pt counter electrode without adding iodine and achieved a moderately higher cell efficiency (3.15\%), as compared to that containing bare PMII (0.26\%).
\end{abstract}

\section{Introduction}

In general, a typical DSSC is composed of three adjacent thin layers: a mesoporous oxide film, such as $\mathrm{TiO}_{2}$, supported on transparent conducting glass dye molecules, such as ruthenium bipyridyl derivatives which are sensitive to visible light in the solar spectrum, and an electrolyte solution containing iodide and triiodide ions as a redox mediator to reduce the oxidized dye molecules. The three layers are sandwiched together by a second conducting glass covered with platinum $[1,2]$. However, leakage and the volatilization of organic solvent-based electrolytes have restricted practical applications of DSSC. Room-temperature ionic liquids (RTILs) have become attractive candidates for replacing organic solvents because of their negligible vapor pressure, high thermal stability, wide electro-chemical window, and high ionic conductivity [3-7]. Nevertheless, the viscosity of RTIL is still much higher than that of organic solvents, including acetonitrile (ACN) and 3-methoxypro-pionitrile (MPN) and has resulted in lower power conversion efficiencies because of the RTIL poor ionic diffusion ability.

Carbon nanotube coated by conjugated conducting polymer nanocomposites is worthy conducting hybrid materials, which are often used in organic field effect transistor, solar cells, sensors, electrochromic devices, and light emitting diodes [8-12]. Here, the MWNT-PAni nanocomposites were utilized to ionic liquid-based electrolyte to form the extended electron transfer surface (Scheme 1) from the counter electrode's surface to the bulk electrolyte, in order to facilitate electron transfer and, thereby, decrease the dark current from the working electrode to the electrolyte. 


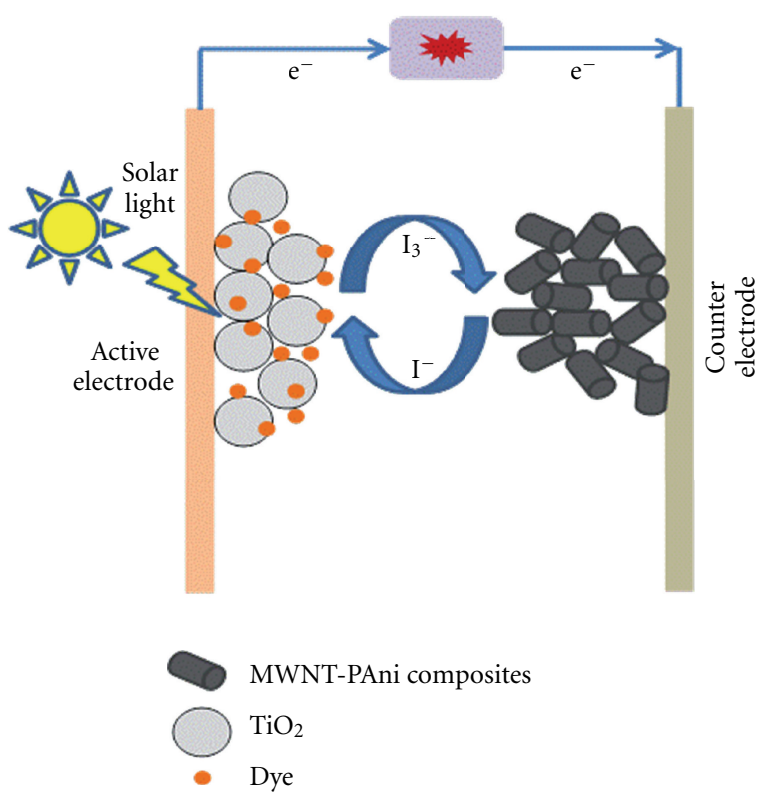

Scheme 1: Schematic design of the charge transport processes in a typical DSSC with a quasi-solid-state composite electrolyte containing the MWNT-PAni hybrid composites and IL.

In the present study, MWNT-PAni composites have been used in DSSC, and the effect of MWNT-PAni composites addition in the solvent-free ionic liquid electrolyte without the incorporation of iodine was studied.

\section{Experimental}

The following chemicals were purchased and used without further purification: 1-methyl-3-propyl-imidazolium iodide (MPII, from Merck), tert-butyl alcohol (Fluka), and acetonitrile (ACN, 99.99\%, Aldrich). MWNT (>95 vol. grade) produced by CVD method, diameter: $10-20 \mathrm{~nm}$, length: 10-50 $\mu \mathrm{m}$. Aniline monomer (98\%, Aldrich) was distilled under a reduced pressure and kept below $0^{\circ} \mathrm{C}$ prior to use. Hydrochloric acid, ammonium persulfate (APS, $\left(\mathrm{NH}_{4}\right)_{2} \mathrm{~S}_{2} \mathrm{O}_{8}$ ), and other organic solvents were bought from Aldrich as reagent grade and used without further purification.

The conducting MWNT-PAni hybrid composites were synthesized as per our reported work [13]. The instruments used for this work included a field emission scanning electron microscope (FE-SEM) (Hitachi Model S-4300), a transmission electron microscope (TEM) (Philips model CM 200) with an Acc. Voltage of $200 \mathrm{kv}$. The room-temperature conductivity of the pressed pellets was measured by the fourpoint probe method using a Jandel engineering instrument, Model CMT-SR1060N. The composite electrolyte was prepared by mixing the solid powder of MWNT-PAni, PMII, and $\mathrm{ACN}$ in a weight ratio of $1: 7: 7 . \mathrm{ACN}$ was added to the composite to improve the mixing and was removed on a hot plate at a temperature of $90^{\circ} \mathrm{C}$.

A double-layer $\mathrm{TiO}_{2}$ photoelectrode $(10+5) \mathrm{mm}$ in thickness with a $10 \mathrm{~mm}$ thick nanoporous layer and a $5 \mathrm{~mm}$ thick scattering layer (area: $0.25 \mathrm{~cm}^{2}$ ) was prepared by screen printing on a conducting glass substrate. A dye solution of $3 \times 10^{-4} \mathrm{M}$ concentration in acetonitrile-tert-butyl alcohol $(1 / 1, v / v)$ was used to uptake the dye onto the $\mathrm{TiO}_{2}$ film. Deoxycholic acid (DCA) $(20 \mathrm{mM})$ as a coadsorbent was added into the dye solution to prevent aggregation of the dye molecules. The $\mathrm{TiO}_{2}$ films were immersed into the dye solution and then kept at $25^{\circ} \mathrm{C}$ for $30 \mathrm{~h}$. Photovoltaic measurements were performed in a two-electrode sandwich cell configuration. A $30 \mu \mathrm{m}$ thick surlyn spacer was put on the dye-deposited $\mathrm{TiO}_{2}$ electrode and attached by heating. The MWNT-PAni/MPII hybrid composite electrolyte was then put onto the dye sensitized $\mathrm{TiO}_{2}$ film at $85^{\circ} \mathrm{C}$ to ensure that the PMII can penetrate well into the porous structure and remove the residual ACN. The dye-deposited $\mathrm{TiO}_{2}$ electrode with the MWNT-PAni/MPII hybrid composite electrolytes was assembled with a platinum-coated conducting glass electrode and sealed by heating the polymer frame. The electrolytes used for liquid cell were composed of $0.6 \mathrm{M}$ dimethylpropylimidazolium iodide (DMPII), 0.05 $\mathrm{M} \mathrm{I}_{2}$, and $0.1 \mathrm{M}$ LiI in acetonitrile.

Photocurrent density-voltage (I-V) of sealed solar cells was measured under standard air mass 1.5 sunlight (100 $\mathrm{mW} \mathrm{cm}{ }^{-2}$, WXS-155S-10: Wacom Denso Co., Japan) with a metal mask of $0.25 \mathrm{~cm}^{2}$. The photovoltaic parameters, that is, short circuit current $\left(J_{\mathrm{SC}}\right)$, open circuit voltage $\left(V_{\mathrm{OC}}\right)$, fill factor $(\mathrm{FF})$, and power conversion efficiency $(\eta)$ were estimated from I-V characteristics under illumination. Monochromatic incident photon-to-current conversion efficiency (IPCE) spectra were measured with a monochromatic incident light of $1 \times 10^{16}$ photons $\mathrm{cm}^{-2}$ in director current mode (CEP-2000BX, Bunko-Keiki).

\section{Results and Discussion}

An ionic liquid usually has favorable properties from the viewpoint of a DSSC, such as negligible vapor pressure, high thermal stability, a wide electrochemical potential window, and high ionic conductivity [14-18]. Conducting polymercoated carbon nanotubes are notable materials, which are being widely studied because of their extraordinary electronic and mechanical properties. Considering these aspects, an incombustible and nonvolatile PMII and MWNT-PAni composites, were incorporated into DSSC for this study (Scheme 1). It is expected that this IL would allow perfect contact at the interface between the dye-coated porous $\mathrm{TiO}_{2}$ and the extended electron transfer material [19], that is, MWNT-PAni composites. The carbon material in the iodine-free composite electrolyte serves simultaneously as a charge transporter in the electrolyte and as a catalyst for electrochemical reduction of $\mathrm{I}_{3}{ }^{-}$ions [20]. The iodide anionbased IL can provide sufficient $\mathrm{I}^{-}$for the regeneration of oxidized dye under illumination; $\mathrm{I}^{-}$in turn oxidizes to $\mathrm{I}_{3}{ }^{-}$, which can be reduced back to $\mathrm{I}^{-}$at the carbon material.

A typical morphology of MWNT-PAni nanocomposites synthesized by the in situ chemical polymerization method was investigated using scanning electron microscopes (Figure 1). In the Figure 1(a), the FE-SEM image 


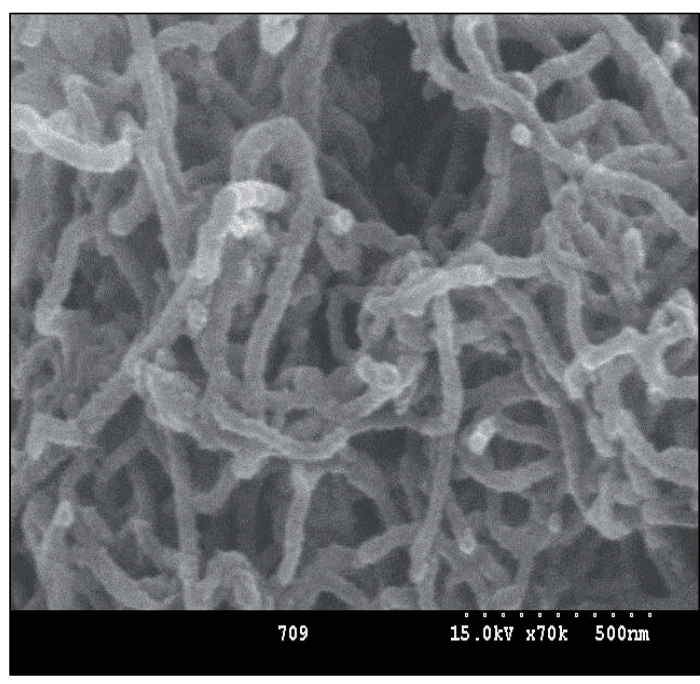

(a)

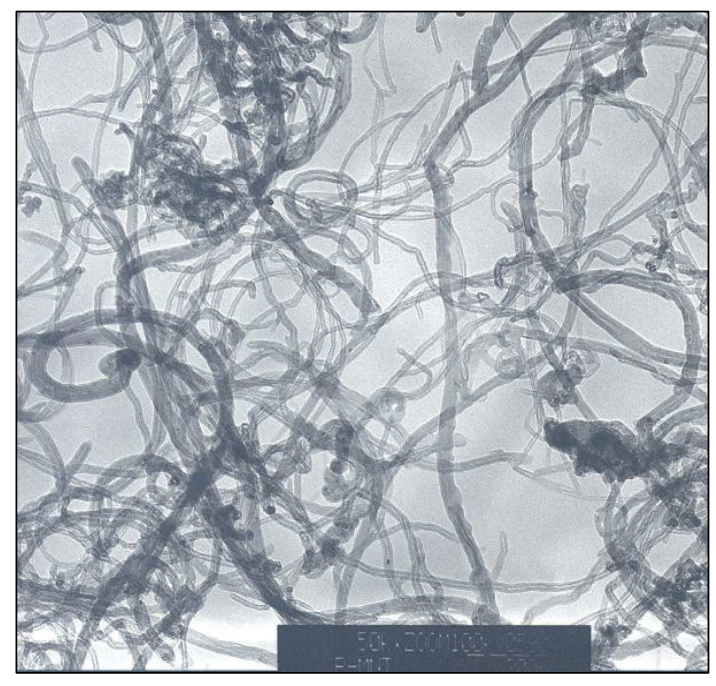

(b)

FIgURE 1: (a) FE-SEM and (b) TEM images of MWNT-PAni composites.

proofs a uniform existence of carbon nanotube and polymer in the MWNT-PAni nanocomposites. A tubular morphology of MWNT- PAni nanocomposites was also identified by using TEM scanning, as shown in Figure 1(b). Microscopic characterizations showed that there was clear indication of interfacial entrapment between the PAni and MWNT; the conducting polymer is coated on the surface of the carbon nanotube. Here, the tubular inner part (core) is mainly the compound of MWNT, and the outer coated surface (shell) is conducting polyaniline with the variable thicknesses (20-50 $\mathrm{nm}$ diameters), and their external surfaces are not smooth.

The atomic percents of the $\mathrm{C}, \mathrm{N}$, and $\mathrm{H}$ are $74.28,5.74$, and 2.75, respectively, for MWNT-PAni composites by the elemental analysis (EA) which reveal that carbon nanotube and polyaniline both are present in the sample. In general, electrical conductivity may be taken as a function of the conjugation length of the polymer, and the amount of active dopant present in the polymer, as the number of charge carriers depends upon the extent of the dopant concentration, provided that other factors remain unchanged. A powder sample of $0.02 \mathrm{~g}$ was loaded and pressed into a pellet $1.2 \mathrm{~cm}$ in diameter and a pressure of $170 \mathrm{~atm}$ by a manual hydraulic press for $10 \mathrm{~min}$. Then, the electrical conductivity of the pellets was measured by a standard four-point probe method, connected to a Keithley voltmeter-constant current source system. The conductivity of the resulting MWNTPAni composites at room temperature is $1.53 \mathrm{~S} / \mathrm{cm}$, which is higher than that of the pristine PAni $(\sim 0.18 \mathrm{~S} / \mathrm{cm})$, which is synthesized without MWNT, under the same conditions. The combination of PAni with MWNT has effectively increased the conductivity, an order of magnitude for the MWNTPAni composites, comparing with its counterpart bulk PAni powders.

The short-circuit photocurrent density $\left(J_{\mathrm{SC}}\right)$, opencircuit photovoltage $\left(V_{\mathrm{OC}}\right)$, fill factors $(\mathrm{FF})$, and overall cell
TABLE 1: Photovoltaic properties of the DSCs with MWNTPAni/PMII composite electrolyte and with bare PMII electrolyte using Pt/ITO as counter electrode ${ }^{\mathrm{a}}$.

\begin{tabular}{lcccc}
\hline Electrolyte & $J_{\mathrm{SC}}\left(\mathrm{mA} \mathrm{cm}^{-2}\right)$ & $V_{\mathrm{OC}}(\mathrm{V})$ & $\mathrm{FF}$ & $\eta(\%)$ \\
\hline PMII & 1.32 & 0.602 & 0.33 & 0.26 \\
MWNT-PAni/PMII & 9.87 & 0.560 & 0.57 & 3.15 \\
Liquid electrolyte $^{\mathrm{b}}$ & 15.21 & 0.701 & 0.72 & 7.68 \\
\hline
\end{tabular}

${ }^{a}$ Conditions: sealed cells; dye: N719; coadsorbate: DCA 40 mM; photoelectrode: $\mathrm{TiO}_{2}\left(0.25 \mathrm{~cm}^{2}\right)$; irradiated light: AM 1.5 solar light $\left(100 \mathrm{mWcm}^{-2}\right)$. $J_{\mathrm{SC}}$ : short-circuit photocurrent density; $V_{\mathrm{OC}}$ : open-circuit photovoltage; FF: fill factor; $\eta$ : total power conversion efficiency. ${ }^{b}$ Liquid electrolyte was composed of $0.6 \mathrm{M}$ dimethylpropyl-imidazolium iodide (DMPII), $0.05 \mathrm{M} \mathrm{I}_{2}$, and $0.1 \mathrm{M} \mathrm{LiI}$ in acetonitrile.

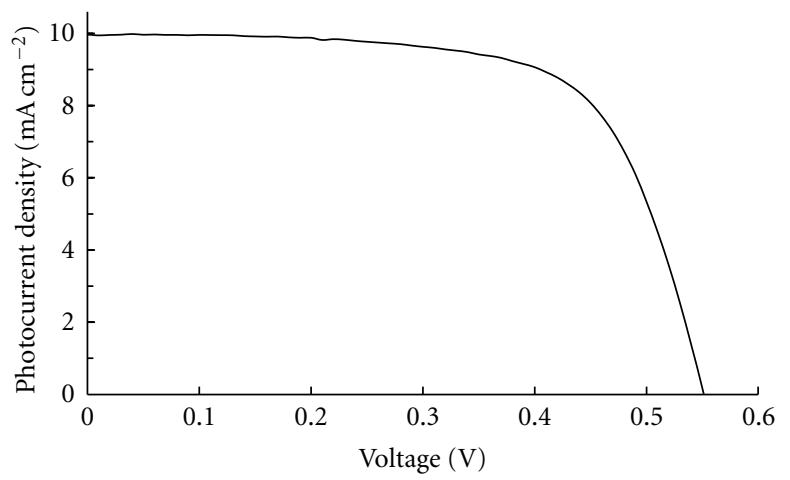

FIGURE 2: Photocurrent-voltage characteristics of DSCs with MWNT-PAni/PMII composite electrolyte at AM 1.5 illuminations (light intensities: $100 \mathrm{~mW} \mathrm{~cm}^{-2}$ ).

efficiencies $(\eta)$ of the DSCs under AM $1.5 \mathrm{G}$ simulated solar light at a light intensity of $100 \mathrm{~mW} \mathrm{~cm}^{-2}$ using MWNTPAni/PMII composite electrolyte and using bare PMII as electrolyte are summarized in Table 1 . Figure 2 shows the 


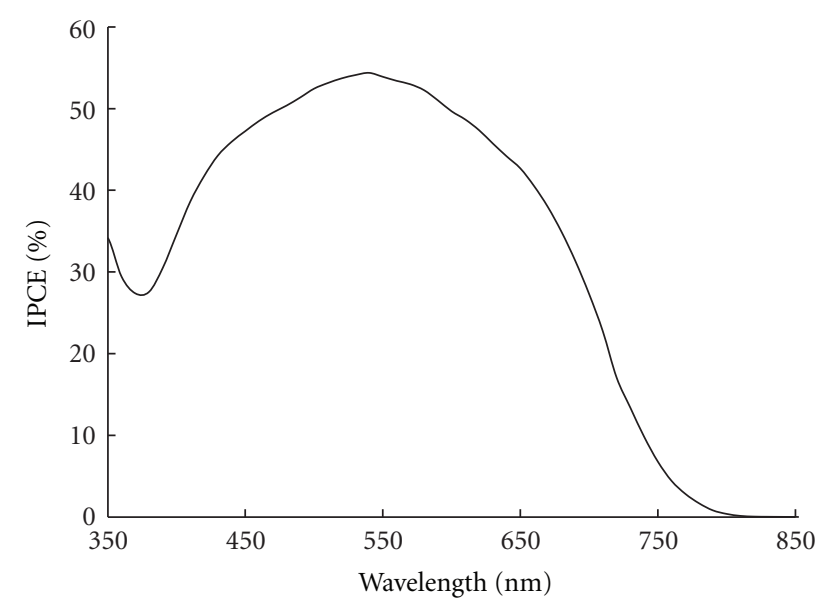

FIgURE 3: Photocurrent action spectra of the DSCs with MWNTPAni/PMII composite electrolyte. The incident photon-to-current conversion efficiency is plotted as a function of wavelength. A sandwich-type sealed cell configuration was used to measure this spectrum.

photocurrent density-voltage performance for DSCs based on MWNT-PAni/PMII device. The MWNT-PAni/PMII electrolyte containing solar cell showed high DSCs performance showing short-circuit photocurrent density of $9.87 \mathrm{~mA} \mathrm{~cm}^{-2}$, an open-circuit photovoltage of $0.560 \mathrm{~V}$, and a fill factor of 0.57 , corresponding to an overall conversion efficiency $(\eta)$ of $3.15 \%$ under standard AM 1.5 irradiation $\left(100 \mathrm{~mW} \mathrm{~cm}^{-2}\right)$, which is remarkably higher than that of bare PMII device $(0.26 \%)$ under the same experimental conditions. The low device efficiency of bare PMII device is due to significant decrease in $J_{\mathrm{SC}}$. The presence of MWNT-PAni composite materials in PMII facilitates electron transfer from counter electrode to $\mathrm{I}_{3}{ }^{-}$, which enables the $\mathrm{I}^{-} / \mathrm{I}_{3}{ }^{-}$redox couple to work more efficiently than they would in the absence of MWNT-PAni [20]. Under the same experimental device conditions, solar cells with iodine based liquid electrolyte showed higher overall conversion efficiency $(\eta)$ of $7.68 \%$. Conversion of iodine containing liquid electrolyte to quasisolid MWNT-PAni/PMII led to decrease in the $J_{\mathrm{SC}}$ from 15.21 to $9.87 \mathrm{~mA} \mathrm{~cm}^{-2}$, the $V_{\text {oc }}$ decrease from 0.70 to 0.56 , and the fill factor decrease from 0.72 to 0.57 because of marked increase in viscosity for MWNT-PAni/PMII device compare to liquid electrolyte device.

Figure 3 shows the monochromatic incident photon to current conversion efficiency (IPCE) for DSCs based on MWNT-PAni/PMII composite. MWNT-PAni/PMII device shows the maximum IPCE of $54 \%$ at $550 \mathrm{~nm}$. Here, the integrated $J_{\mathrm{SC}}$ value from IPCE was the same value obtained $9.87 \mathrm{~mA} \mathrm{~cm}^{-2}$ from the I-V measurement. The low photon-to-current conversion efficiency in the MWNTPAni/PMIIelectrolyte-based device may be due to inefficient charge transport properties in the composite electrolyte.

\section{Conclusion}

A quasi-solid-state DSSC was developed using the hybrid MWNT-PAni nanocomposites as an electrolyte layer without adding the conventional iodine electrolytes. A moderately higher efficiency $(3.15 \%)$ of solid-state DSSC was achieved with the hybrid MWNT-PAni nanocomposites and PMII under AM1.5 full sunlight. It is revealed that the MWNTPAni nanocomposite electrolyte serves simultaneously as the filler for physical gelation of electrolyte and as the catalyst for electrochemical reduction of $\mathrm{I}_{3}^{-}$.

\section{Acknowledgments}

The authors gratefully acknowledge the financial support from NPST program by King Saud University of project no. 10-NAN1021-02. The authors declare no conflict of interests.

\section{References}

[1] A. Hagfeldt and M. Gratzel, "Molecular photovoltaics," Accounts of Chemical Research, vol. 33, no. 5, pp. 269-277, 2000.

[2] L. Han, A. Islam, H. Chen et al., "High-efficiency dye-sensitized solar cell with a novel co-adsorbent," Energy and Environmental Science, vol. 5, pp. 6057-6060, 2012.

[3] J. M. Pringle, J. Golding, C. M. Forsyth, G. B. Deacon, M. Forsyth, and D. R. MacFarlane, "Physical trends and structural features in organic salts of the thiocyanate anion," Journal of Materials Chemistry, vol. 12, no. 12, pp. 3475-3480, 2002.

[4] P. Wang, S. M. Zakeeruddin, J. E. Moser, and M. Gratzel, "A new ionic liquid electrolyte enhances the conversion efficiency of dye-sensitized solar cells," The Journal of Physical Chemistry $B$, vol. 107, no. 48, Article ID 2003, pp. 13280-13285.

[5] C. P. Fredlake, J. M. Crosthwaite, D. G. Hert, S. N. V. K. Aki, and J. F. Brennecke, "Thermophysical properties of imidazoliumbased ionic liquids," Journal of Chemical and Engineering Data, vol. 49, no. 4, pp. 954-964, 2004.

[6] P. Wang, S. M. Zakeeruddin, R. H. Baker, and M. Gratzel, "A binary ionic liquid electrolyte to achieve $\geq 7 \%$ power conversion efficiencies in dye-sensitized solar cells," Chemistry of Materials, vol. 16, no. 14, pp. 2694-2696, 2004.

[7] P. Wang, S. M. Zakeeruddin, J. E. Moser, R. H. Baker, and M. Gratzel, "A solvent-free, $\mathrm{SeCN}^{-} /(\mathrm{SeCN})_{3}^{-}$based ionic liquid electrolyte for high-efficiency dye-sensitized nanocrystalline solar cells," Journal of the American Chemical Society, vol. 126, no. 23, pp. 7164-7165, 2004.

[8] W. U. Huynh, J. J. Dittmer, and A. P. Alivisatos, "Hybrid nanorod-polymer solar cells," Science, vol. 295, no. 5564, pp. 2425-2427, 2002.

[9] M. R. Karim, C. J. Lee, and M. S. Lee, "Synthesis and characterization of conducting polythiophene/carbon nanotubes composites," Journal of Polymer Science A, vol. 44, no. 18, pp. 5283-5290, 2006.

[10] M. R. Karim, J. H. Yeum, M. S. Lee, and K. T. Lim, "Synthesis of conducting polythiophene composites with multi-walled carbon nanotube by the $\gamma$-radiolysis polymerization method," Materials Chemistry and Physics, vol. 112, no. 3, pp. 779-782, 2008.

[11] M. Fu, Y. Zhu, R. Tan, and G. Shi, "Soluble polythiophenes with pendant fullerene groups as double cable materials for photodiodes," Advanced Materials, vol. 13, no. 24, pp. 1871-1874, 2001.

[12] M. R. Karim, A. Islam, S. P. Singh, and L. Han, "Quasi solidstate dye-sensitized solar cell incorporating highly conducting polythiophene-coated carbon nanotube composites in ionic 
liquid," Advances in OptoElectronics, vol. 2011, Article ID 357974, 7 pages, 2011.

[13] M. R. Karim, C. J. Lee, Y.-T. Park, and M. S. Lee, "SWNTs coated by conducting polyaniline: synthesis and modified properties," Synthetic Metals, vol. 151, no. 2, pp. 131-135, 2005.

[14] J. M. Pringle, J. Golding, C. M. Forsyth, G. B. Deacon, M. Forsyth, and D. R. MacFarlane, "Physical trends and structural features in organic salts of the thiocyanate anion," Journal of Materials Chemistry, vol. 12, no. 12, pp. 3475-3480, 2002.

[15] C. P. Fredlake, J. M. Crosthwaite, D. G. Hert, S. N. V. K. Aki, and J. F. Brennecke, "Thermophysical properties of imidazoliumbased ionic liquids," Journal of Chemical and Engineering Data, vol. 49, no. 4, pp. 954-964, 2004.

[16] D. R. MacFarlane, S. A. Forsyth, J. Golding, and G. B. Deacon, "Ionic liquids based on imidazolium, ammonium and pyrrolidinium salts of the dicyanamide anion," Green Chemistry, vol. 4, no. 5, pp. 444-448, 2002.

[17] J. G. Huddleston, A. E. Visser, W. M. Reichert, H. D. Willauer, G. A. Broker, and R. D. Rogers, "Characterization and comparison of hydrophilic and hydrophobic room temperature ionic liquids incorporating the imidazolium cation," Green Chemistry, vol. 3, no. 4, pp. 156-164, 2001.

[18] P. Wang, S. M. Zakeeruddin, J. E. Moser, R. H. Baker, and M. Gratzel, "A solvent-free, $\mathrm{SeCN}^{-} /(\mathrm{SeCN})_{3}^{-}$based ionic liquid electrolyte for high-efficiency dye-sensitized nanocrystalline solar cells," Journal of the American Chemical Society, vol. 126, no. 23, pp. 7164-7165, 2004.

[19] C. P. Lee, K. M. Lee, P. Y. Chen, and K. C. Ho, "On the addition of conducting ceramic nanoparticles in solvent-free ionic liquid electrolyte for dye-sensitized solar cells," Solar Energy Materials and Solar Cells, vol. 93, no. 8, pp. 1411-1416, 2009.

[20] C. P. Lee, P. Y. Chen, R. Vittal, and K. C. Ho, "Iodine-free high efficient quasi solid-state dye-sensitized solar cell containing ionic liquid and polyaniline-loaded carbon black," Journal of Materials Chemistry, vol. 20, no. 12, pp. 2356-2361, 2010. 

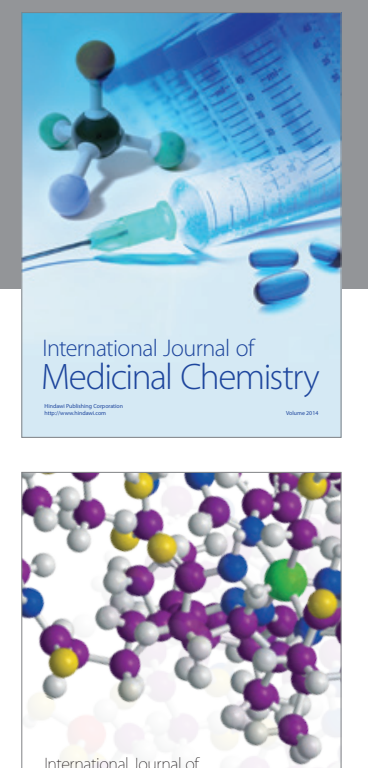

\section{Carbohydrate} Chemistry

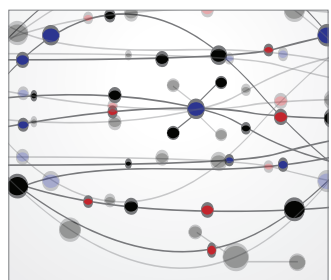

The Scientific World Journal
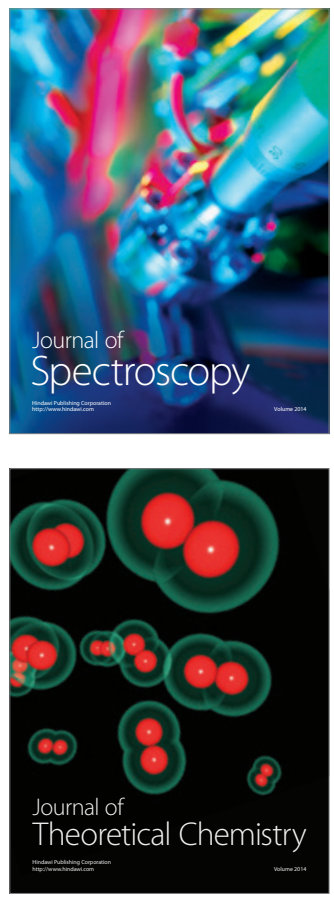
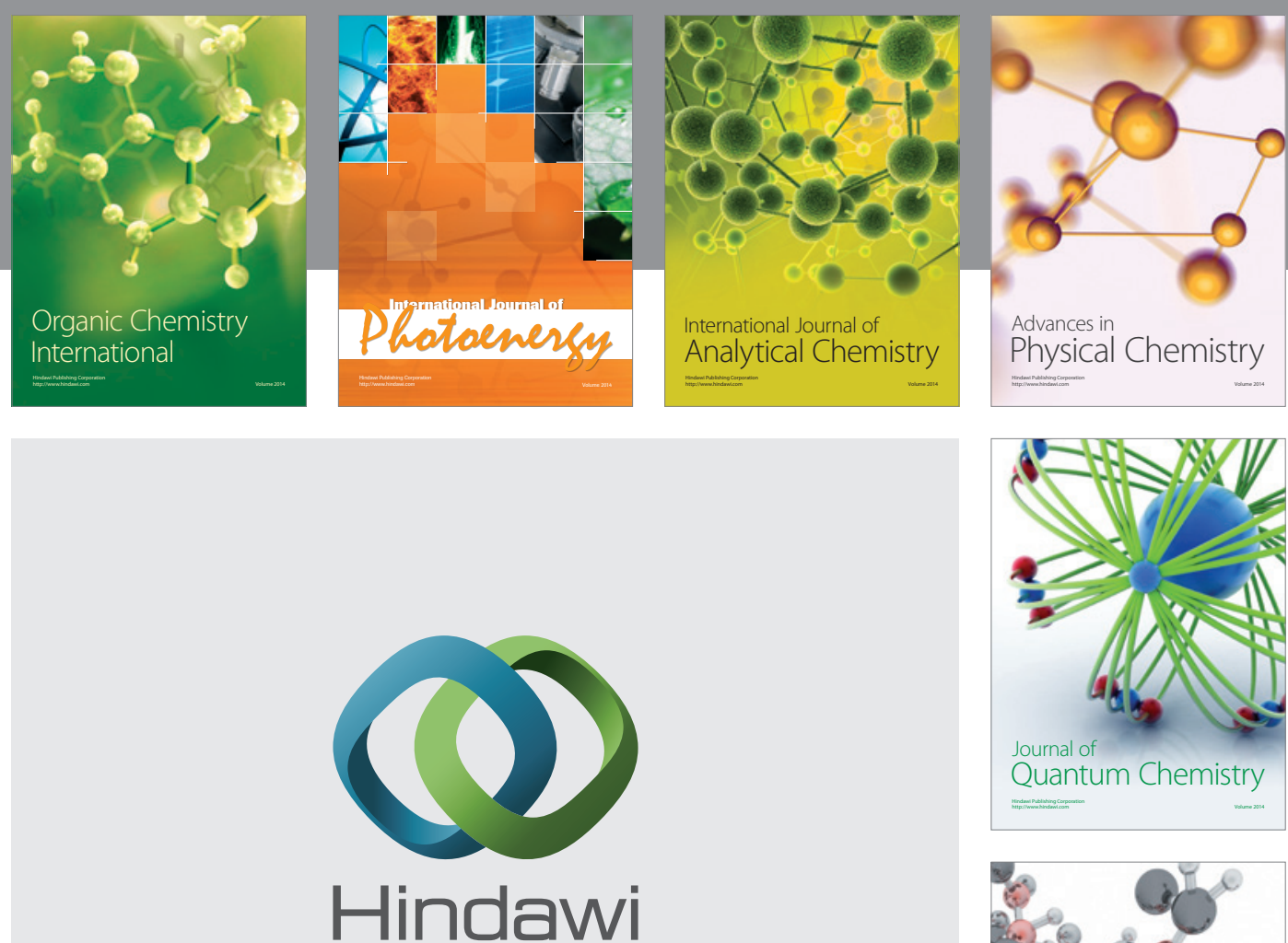

Submit your manuscripts at

http://www.hindawi.com

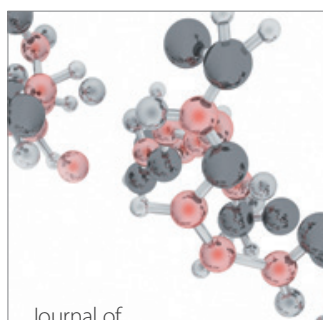

Analytical Methods

in Chemistry

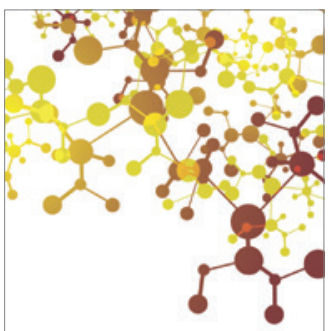

Journal of

Applied Chemistry

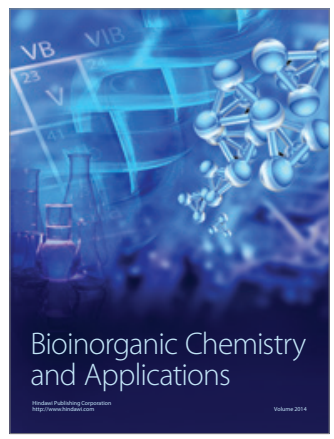

Inorganic Chemistry
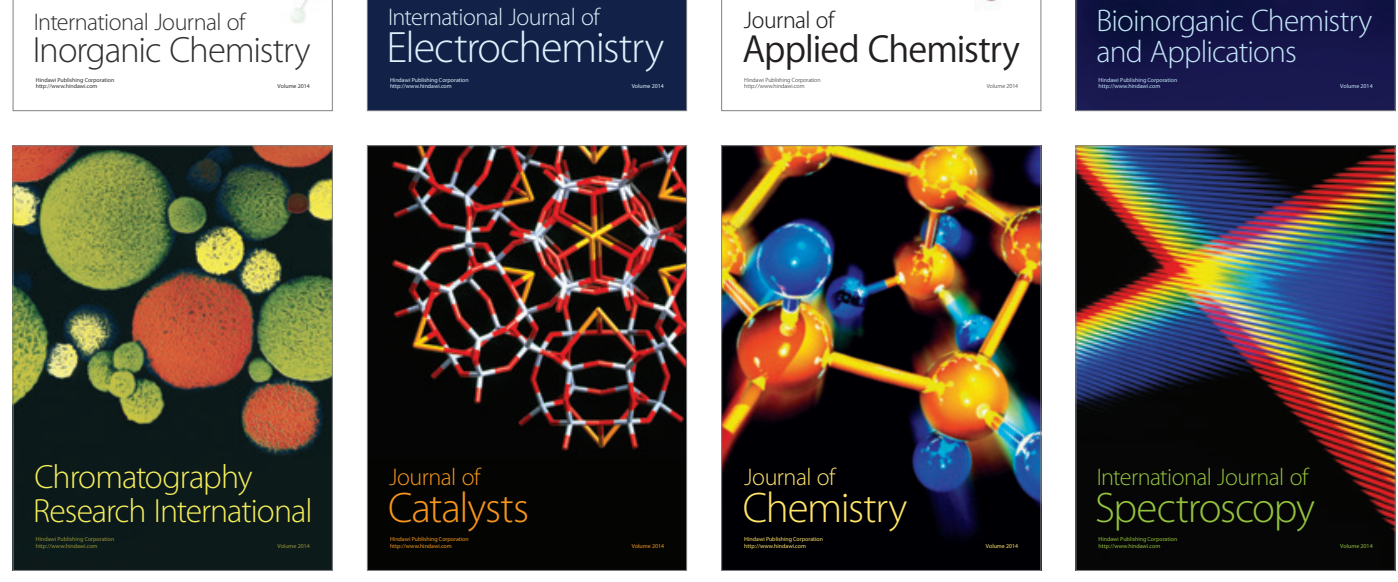